\title{
Research on Search-Based Scheduling and Allocating Algorithm
}

\author{
Fan Zhang, Yueli Li, Chen Chen \\ School of Information Science and Technology, Agricultural University of Hebei \\ ellenzhang0911@126.com,li_yueli@163.com,chenchen020110@sina.com
}

\begin{abstract}
Trans-regional operation with Chinese characteristics, which is a unique farm machinery social service, appeared in our country. How to select scheduling paths and farmland for obtaining the maximum profits is difficult to make decision. The scheduling and allocating income model with the goal of high-income and low-cost is established in the paper. Then the concept of parallel tasks is defined, judgment of parallel tasks, generation of scheduling path graph with heuristic information and establishment of combined scheduling and allocating rules are studied in the paper. Multi-machinery simultaneous scheduling and allocating algorithm and scheduling and allocating in demand algorithm are proposed according to the characteristic of multi-machinery and multi-point operation. Scheduling and allocating strategies of parallel tasks are improved and search-based scheduling and allocating algorithm are put forward. The feasibility and validity of search-based scheduling and allocating algorithm are further verified at the aspects of parallel task, amount of farmland and farm machinery demand.
\end{abstract}

Keywords: simultaneous, parallel tasks, scheduling and allocating in demand, search-based scheduling algorithm

\section{Introduction}

China is a huge agricultural country with complex and varied terrain and large latitude span. The geographical and climatic characteristics make harvest and planting time of crops form gradient. So it provides natural conditions for carrying out agricultural social service. However, the difficulty of large-scale agricultural operations is increased and the efficiency of agricultural operations is reduced because of land decentralized management after the implement of the household responsibility system. Chinese agricultural economy level is not high and the financial level is not strong. It will result in a waste of resources and increase farmers' economic pressure if every household purchase agricultural machinery. So the households who provide agricultural services are emerged and variety of agricultural service organizations are gradually formed. Currently, agricultural service organizations are the major force in the agricultural social services ${ }^{[1-3]}$. Service across regions providing by agricultural service organizations, is an important way to resolve a contradiction between small-scale production and large-scale mechanized operations. However, there are many problems in agricultural machinery social service. Inadequate and inaccurate agricultural machinery information leads unreasonable agricultural machinery allocation in temporal and regional field. Decentralized machine disturb the order of agricultural machinery operations ${ }^{[4-5]}$. The machine hand has allocated farm machinery by subjective experience without scientific and reasonable deployment plan. Too much farm machinery crowd in some region so that there are not enough farmland to reap and much farm machinery is idle. Other region is lack of farm machinery and need more farm machinery to complete the harvest. All kinds of agricultural holdings, fuel and labor costs have increased and the market is saturated with the implementation of farm machinery purchase subsidy policy. Therefore, the income and the efficiency of machinery social service have reduced every year. 
Agricultural technology development and management of different countries are in different ways depending on different situation of agriculture. Developed countries have high levels of agricultural equipment and mechanization. With the development of modern agriculture, the United States, Germany, France, Japan and other developed countries have established a relatively perfect agricultural social service system. There are some representative agricultural service organizations. Such as CUMA in France, agricultural machinery ring in German, agricultural mechanized bank in Japan and leasing companies of agricultural machinery in United States. These service organizations focus on the common use and equipping problems of agricultural machinery ${ }^{[6]}$.

Agricultural machinery operation service train across region system, which is developed by Agricultural Mechanization Management Division of China's ministry of agriculture and provide convenient, fast, true and accurate information for farmers, is an important channel and carrier of agricultural machinery operations information services. The trans-regional information service center, which is launched by Foton Lovol in support of China's ministry of agriculture, sends 10 categories of services SMS including agriculture, agricultural machinery, weather, traffic, fuel supply, public health, public security, technical supervision, industry and commerce and integrated information. Farm SMS center based on GPS and GSM, which is designed and implemented in Peng Bo's research ${ }^{[7]}$, links with GPS and the farm dispatch center. Therefore, agricultural machinery can be scheduled suitably according to the actual situation. In Shenquanquan's paper ${ }^{[8]}$, Jiaxing City is as an example to describe how to schedule and allocate the existing agricultural resources including local and foreign agricultural machinery suitably and how to maximize the efficiency of agricultural machinery through networks. There are several parts in the agricultural machinery information service system including dynamic information services of farmland, agricultural machinery trade train, troubleshoot problems and other expert groups. Digital dispatching system, which use $3 \mathrm{~S}$ as the core technology and has applied in agricultural machinery management, is introduced in Guan congjiang's paper ${ }^{[9]}$. Agricultural Job delegate decision-support system, which can quickly make cross-agricultural job scheduling solutions, is introduced in Guo hongpeng's paper ${ }^{[10]}$.

The above researches provide a variety of information of agricultural operations, or macro scheduling and allocating strategies. However, they don't provide specific and practical solutions for machinery owners. Actually, the machinery owners decide how to choose region and location of farmland independently according to the relevant scheduling and allocating information. There are many influencing factors, including time, location, road conditions, machinery type and quantity, operational capability, price, weather condition and subjective factors of machinery owners. Therefore agricultural machinery trans-regional scheduling and allocating is a complex issue. There are no similar studies reported at home and abroad. Research and development of agricultural machinery scheduling and allocating, which have important significant and great practical value, is the inevitable trend of development of agricultural mechanization. Based on the above research of agricultural machinery scheduling and allocating, it is studied how to provide scientific and reasonable allocating schemes for farmland owners in order to increase owner's income as large as possible and to reduce scheduling costs as small as possible. The agricultural machinery and farmland is given in this paper, it is mainly studied how to obtain scientific and reasonable allocating scheme with the service revenue as much as possible and the scheduling costs as small as possible.

\section{Problem Statement and Preliminaries}

Agricultural departments release specific farmland harvest information. It mainly includes farmland location, time service window of farmland, farmland area, and harvest 
price. The machinery owners choose some farmland independently with their agricultural machinery service capacity and quantity. It mainly researches on scheduling and allocating algorithm to find the optimal scheduling scheme after analyzing and calculating feasible scheme in this paper. The object is to increase the machinery owners' service income and decrease the deployment service cost in the allowable time window. The agricultural machinery scheduling model is proposed in the paper.

In order to build the scheduling model, the variances are defined as following.

The amount of agricultural machinery that the machinery owner has is $m$.It is denoted as agricultural machinery $i, 1 \leq i \leq m$.

The amount of farmland that the machinery owner has chosen is $n$.It is denoted as farmland $j, 1 \leq j \leq n$.

The harvest capacity per unit time of agricultural machinery is denoted as $r$.

The area of farmland $j$ is denoted as $S_{j}, 1 \leq j \leq n$.

The harvest price per unit area of farmland $j$ is denoted as $C_{j}, 1 \leq j \leq n$.

The allowable time window of farmland $j$ is denoted as $\left[\mathrm{a}_{\mathrm{j}}, \mathrm{b}_{\mathrm{j}}\right], a_{j}$ represents the earliest time that task $j$ can be serviced, $b_{j}$ represents the last time that task $j$ should be completed.

$t_{i j}$ represents the scheduling time from node $i$ to node $j$ in the network model.

$d$ represents the scheduling cost per unit time.

The arrival time of node $j$ from node $i$ is denoted as $\mathrm{AT}_{\mathrm{ij}}$.

The completion time of node $j$ is denoted as $\mathrm{DT}_{\mathrm{j}}$.

The waiting cost per unit time is denoted as S.

The amount of agricultural machinery that allocated from node $i$ to node $j$ is denoted as $\mathrm{n}_{\mathrm{ij}}$.

$$
\mathrm{Z}_{i j}=\left\{\begin{array}{l}
1, \text { waiting time exist fromi to } \mathrm{j} \\
0, \text { waiting time doesn't exist fromi to } \mathrm{j}
\end{array}\right\} .
$$

Define the latest arrival time $\mathrm{ATL}_{j}=b_{j}-\frac{S_{j}}{\sum_{i=1}^{m} r_{i}}$.

Define the minimum demand capacity of farmland $j$ is $Q_{j}=\frac{S_{j}}{b_{j}-a_{j}}$, the minimum

demand amount of every farmland is $M_{j}=\left[\frac{Q_{j}}{r}\right]+1$.

The mathematic model of the scheduling and allocation problem is established.

$\operatorname{Max} \mathrm{R}=\sum_{i=1}^{n} C_{i} S_{i}-d \sum_{j=0}^{n} \sum_{i=0}^{n} t_{i j} n_{i j}-s \sum_{j=1}^{n} \sum_{i=0}^{n}\left(a_{j}-A T_{i j}\right) Z_{i j} n_{i j}$

St. 
$D T_{j} \leq b_{j}$

$\mathrm{DT}_{i}+t_{i j}=A T_{i j}$

$r \sum_{i=0}^{n}\left(D T_{i}-a_{i}\right) n_{i j} Z_{i j}+r \sum_{i=0}^{n}\left(D T_{j}-A T_{i j}\right) n_{i j}\left(1-Z_{i j}\right) \geq S_{j}$

$M_{j} \leq \sum_{i=0}^{n} n_{i j} \leq M$

$\mathrm{Z}_{i j}=\left\{\begin{array}{l}1, a_{j}-A T_{i j}>0 \\ 0, a_{j}-A T_{i j} \leq 0\end{array}\right\}$

The income in the paper means the earnings of reaping the farmland. The scheduling cost includes two parts. One is the scheduling expenses, the other is penalty fees, which means the machinery owner will get penalty when the arrival time of farmland is earlier than its earliest allowable time.

From the scheduling model can be seen, the farmland that chosen by machinery owner, are not necessarily serviced. Maybe the agricultural machinery don't all involve in the scheduling task. The main content of the dissertation is to research on the optimal scheduling scheme for machinery owners, and to assist the machinery owners to obtain the maximal profits in the given situation. From the constraint condition 1, the completion time of node $j$ should be before the latest allowable time. The constraint condition 2 means that the arrival time from $i$ to $j$ equals to completion time of $i$ and the scheduling time from $i$ to $j$. From the constraint condition 3, the total reaping areas of $j$ shouldn't less than the areas of $j$. The amount of agricultural machinery serviced in the node $j$ should be between $\mathrm{M}_{\mathrm{j}}$ and $\mathrm{M}$ in the constraint condition 4. If the arrival time from $i$ to $j$ is earlier than the earliest time, $\mathrm{Z}_{\mathrm{ij}}=1$, otherwise, $\mathrm{Z}_{\mathrm{ij}}=0$ in the constraint condition 5 .

\section{General Scheduling and Allocating Algorithms}

In order to solve the scheduling and allocated problems, this paper adopts the following allocating rules.

Rule1. The muti-machinery allocation strategies means all the agricultural machinery allocated for farmland.

Rule2. The minimal allocation strategies means to allocate the minimal requirement quantities of agricultural machinery for farmland.

\subsection{Multi-Machinery Simultaneous Scheduling and Allocating Algorithm}

Multi-machinery simultaneous scheduling and allocating means all the machinery set out from the original location of agricultural machinery, and allocate machinery for every farmland in proper order until completing all the tasks and return to the original location. Multi-machinery simultaneous scheduling and allocating algorithm proposed in this paper, is noted as $A L G_{l}$. The algorithm thought of $A L G_{I}$ is the farmland is sorted by the early service time and all the agricultural machinery are scheduled for service. The flow of $A L G_{l}$ can be described as follows. 
Step1. The farmland is sorted by the early service time. $j=1, \mathrm{n}$ is the amount of farmland.

Step2. If $j>n$, turn to Step 5 .

Step3. Calculate the completion time $\left(\mathrm{T}_{\mathrm{j}}\right)$ of farmland $j$ by Rule1.

Step4. Allocate agricultural machinery for farmland $\mathrm{j}$ and save the scheduling strategies, $j++$, and turn to Step 2.

Step5. Quit.

\subsection{The Scheduling and Allocating in Demand Algorithm}

Multi-machinery simultaneous scheduling and allocating can shorten the service time of every farmland and will increase the scheduling costs. However, some farmland may need part of machinery to complete tasks. The scheduling and allocating in demand algorithm which is noted as $A L G_{2}$, is proposed in the paper according to the object of with high service revenue and low scheduling costs. The algorithm thought of $A L G_{2}$ is the farmland is sorted by the early service time and the minimum demand amount of agricultural machinery is scheduled for service. The flow of $A L G_{2}$ can be described as follows.

Step1. $j=1, n$ is the amount of farmland.

Step2. If $j>n$, turn to Step5.

Step3. Calculate the completion time $\left(\mathrm{T}_{j}\right)$ of farmland $j$ by Rule2.

Step4. Agricultural machinery is allocated for farmland $j$ by Rule2, $j++$, turn to Step2.

Step5. Quit.

\section{Search-Based Scheduling and Allocating Algorithm.}

Search-based Scheduling and Allocating Algorithm is firstly proposed and the mainly algorithm processes are as follows in this paper. The concept of parallel tasks is defined, judgment of parallel tasks, generation of scheduling path graph with heuristic information and establishment of search-based scheduling and allocating algorithm are studied in the paper. In order to interpret the agricultural machinery and farmland, the explanation is shown in following paper. The farmland is called task. The agricultural machinery held by owners is called resource.

\subsection{The Judgment of Parallel Tasks}

The farmland chosen by machinery owners are sort by the order of earliest start time. The location of the machinery owner is defined as $O$. The ordered farmland is allocated by all the machinery together. If the farmland $\mathrm{F}_{\mathrm{i}+1}$ cannot be completed after having allocated farmland $F_{i}$, then farmland $F_{i}$ and $F_{i+1}$ are parallel tasks. The parallel tasks have the same layer in the paper. Therefore the algorithm of judgment of tasks layer can be described as follows.

Step1. Initialization.

1.1 Sorts the farmland by the ascending order of earliest start time. If the farmland have the same earliest start time, sort them by the order of earliest end time and add them in the queue $Q$.

$1.2 \mathrm{n}$ is the amount of farmland. Initialize Array $\mathrm{A}[n]$, which is used to save the layer of every farmland.

1.3 The layer of $O$ is $0, j=1$. 
Step2. If $j>\mathrm{n}$, turn to Step5.

Step3. Calculate the completion time $T_{j}$ of farmland $j$ by Multi-machinery simultaneous scheduling and allocating algorithm.

Step4. If $\mathrm{T}_{j}>\mathrm{b}_{j}\left(\mathrm{~b}_{j}\right.$ is the last completion time of farmland $\left.j\right)$, then the farmland $\mathrm{F}_{\mathrm{j}-1}$ and $\mathrm{F}_{j}$ have the same layer, $\mathrm{A}[j]=\mathrm{A}[j-1], j++$, turn to Step2. Else $\mathrm{A}[j]=\mathrm{A}[j-1]+1, j++$, turn to Step2.

Step5. Quit.

\subsection{The Generation of Scheduling Path Graph}

The task layers can be obtained through the above algorithm. The next step is how to generate the feasible scheduling diagram. The main thought is as follows. It starts from the layer 0 and connects the resource of layer 0 to every resource of layer 1 and the direction from layer 0 to layer 1.then connects every resource of layer 1 to that of layer 2 and the direction from layer 1 to layer 2. It ends until all the resource is connected and the directed scheduling graph is generated. Therefore the algorithm of generation of scheduling path graph can be described as follows.

Step1. Initialization.

Calculate the task amount of every layers and save in array $\mathrm{L}[\mathrm{m}] . \mathrm{m}$ is the max layer of tasks.

The layer of $O$ is $0 . k=1$.

The tasks are sorted in Queue $Q$.

Step2. If $k>m$, turn to Step7, otherwise $i=\mathrm{L}[k]$.

Step3. If $i>0, j=\mathrm{L}[k+1]$, turn to step 4 , otherwise turn to step 2 .

Step4. If $j>0$, turn to step5.otherwise, $i--$, turn to step3.

Step5. Connect $i$ th task of layer $i$ to $j$ th task of layer $j, j--$, and turn to step4.

Step6. Sort out and generate the final scheduling path graph.

Step7. Quit.

\subsection{Description of the Algorithm}

The final scheduling and allocating will be obtained by the search strategies on every feasible path. Properties of resource are as follows. The first one is location. The location means the original location of resource and farmland. The second one is the state of resources. There are three states. If the location of the resources is $O$, the state of it is defined as 0 . If the resources are being scheduled and allocated, the state of it is defined as 1.The state of the resources is noted as 2 after completing scheduling and allocating tasks and releasing the resources. If the resources have finished the tasks and wait there, the state of it is defined as 2.The third one is the number of available resources. It means the number of idle resources at the current location. The flow of search-based scheduling and allocating algorithm is as follows.

Step1. Initialize the location of original resource is $O$ and the status of resource is 0 .

Step2. Check the task queue $Q$, if $Q$ is null, turn to Step6. Else take out the first task from the queue and turn to Step3.

Step3. Analyze the feasible resource according to the current status of resource. 
3.1 If the resource status is 2 and its amount is not 0 , sorts these resources by the ascending order of distance from the current tasks and then calculate whether the waiting resource can complete the current tasks. If yes, turn to Step4, otherwise, calculate the completed tasks and the left tasks with the late completion time and turn to 3.2.

3.2 If the resource status is 1 and its amount is not 0 , sorts these resources by the ascending order of distance from the current tasks and then calculate whether the resource can complete the current tasks after releasing the previous resources. If yes, turn to Step4, otherwise, calculate the completed tasks and the left tasks with the late completion time and turn to 3.3.

3.3 If the resource status is 0 and its amount is not 0 , sorts these resources by the ascending order of distance from the current tasks and then calculate whether the resource can complete the current tasks. If yes, turn to Step4, otherwise, the resource can not complete the task and delete this task and turn to Step2.

Step4. Allocate the suitable resource for the current tasks with the lowest cost and record the allocating result.

Step5. Update the resource status of current time. Turn to Step2.

Step6. Sort out and obtain the final allocating results.

\section{Experiments and Analysis}

A wheat harvest region is chosen as the case studied in the paper. The machinery owner has six same types agricultural machinery which harvest capacity is $5 \mathrm{hm}^{2}$ per day, the traveling speed is $30 \mathrm{~km} / \mathrm{h}$.

Table 1. Farmland Information based on Machinery Owners' Selection

\begin{tabular}{|c|c|c|c|}
\hline NO of farmland & Areas $\left(\mathrm{hm}^{2}\right)$ & $\begin{array}{c}\text { Service price per } \\
\mathrm{mu}(\text { Yuan })\end{array}$ & Time window \\
\hline$F_{1}$ & 45.0 & 52 & {$[3,5]$} \\
\hline$F_{2}$ & 43.4 & 50 & {$[6,8]$} \\
\hline$F_{3}$ & 47.0 & 50 & {$[7,9]$} \\
\hline$F_{4}$ & 60.0 & 49 & {$[10,13]$} \\
\hline$F_{5}$ & 56.7 & 47 & {$[9,13]$} \\
\hline$F_{6}$ & 44.7 & 50 & {$[13,15]$} \\
\hline$F_{7}$ & 56.4 & 49 & {$[16,20]$} \\
\hline$F_{8}$ & 46.7 & 54 & {$[14,17]$} \\
\hline$F_{9}$ & 49.3 & 50 & {$[22,25]$} \\
\hline$F_{10}$ & 42.9 & 55 & {$[25,28]$} \\
\hline
\end{tabular}

Table 2. The Distances between Farm Machinery Point and Farmland Points (km)

\begin{tabular}{|l|l|l|l|l|l|l|l|l|l|l|l|}
\hline & $O$ & $F_{1}$ & $F_{2}$ & $F_{3}$ & $F_{4}$ & $F_{5}$ & $F_{6}$ & $F_{7}$ & $F_{8}$ & $F_{9}$ & $F_{10}$ \\
\hline$O$ & 0 & 34.7 & 42.0 & 64.3 & 68.6 & 54.6 & 67.9 & 95.7 & 86.6 & 86.2 & 126.0 \\
\hline$F_{1}$ & 34.7 & 0 & 64.2 & 38.6 & 82.4 & 61.4 & 57.6 & 111.9 & 67.9 & 81.3 & 132.6 \\
\hline$F_{2}$ & 42.0 & 64.2 & 0 & 74.0 & 30.0 & 27.7 & 55.8 & 57.4 & 81.5 & 62.4 & 88.9 \\
\hline
\end{tabular}




\begin{tabular}{|l|l|l|l|l|l|l|l|l|l|l|l|}
\hline$F_{3}$ & 64.3 & 38.6 & 74.0 & 0 & 79.8 & 55.4 & 33.3 & 102.2 & 31.1 & 57.3 & 112.4 \\
\hline$F_{4}$ & 68.6 & 82.4 & 30.0 & 79.8 & 0 & 24.5 & 51.3 & 29.9 & 73.7 & 43.1 & 59.2 \\
\hline$F_{5}$ & 54.6 & 61.4 & 27.7 & 55.4 & 24.5 & 0 & 32.8 & 49.0 & 55.7 & 36.5 & 72.5 \\
\hline$F_{6}$ & 67.9 & 57.6 & 55.8 & 33.3 & 51.3 & 32.8 & 0 & 71.1 & 24.9 & 25.5 & 82.6 \\
\hline$F_{7}$ & 95.7 & 111.9 & 57.4 & 102.2 & 29.9 & 49.0 & 71.1 & 0 & 89.7 & 54.2 & 37.4 \\
\hline$F_{8}$ & 86.6 & 67.9 & 81.5 & 31.1 & 73.7 & 55.7 & 24.9 & 89.7 & 0 & 36.6 & 90.0 \\
\hline$F_{9}$ & 86.2 & 81.3 & 62.4 & 57.3 & 43.1 & 36.5 & 25.5 & 54.2 & 36.6 & 0 & 55.6 \\
\hline$F_{10}$ & 126.0 & 132.6 & 88.9 & 112.4 & 59.2 & 72.5 & 82.6 & 37.4 & 90.0 & 55.6 & 0 \\
\hline
\end{tabular}

\subsection{Experiments and Calculation}

Scheduling and allocating schemes are obtained by the three algorithms. And the results are analyzed in the paper. The scheduling result of $A L G_{1}$ is $F_{1} \rightarrow F_{3} \rightarrow F_{5} \rightarrow F_{4} \rightarrow F_{6} \rightarrow F_{8} \rightarrow F_{7}$ $\rightarrow F_{9} \rightarrow F_{10}$, which is shown in Figure 1.

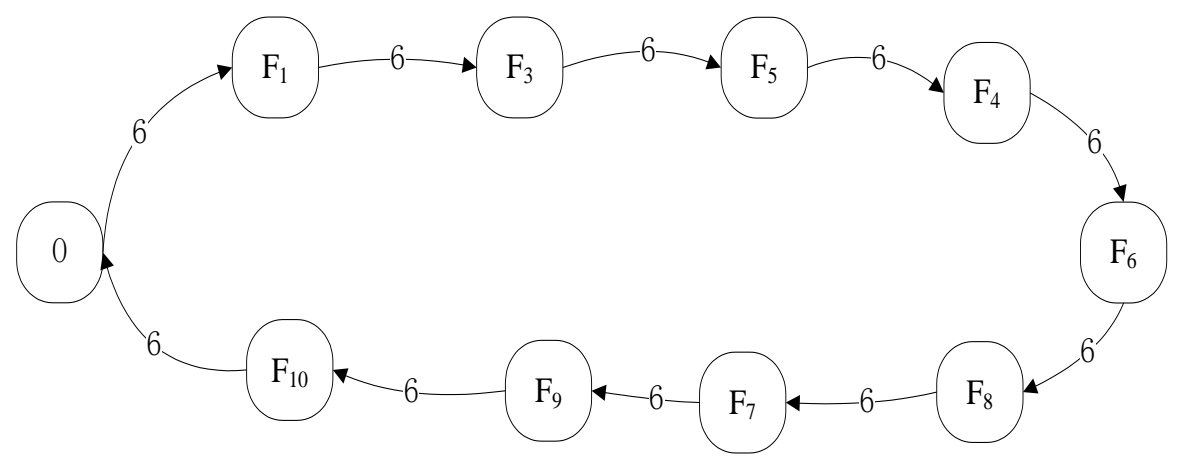

Figure 1. Flow Diagram of Scheduling and Allocating Scheme by ALG1

The scheduling sequence of $A L G_{2}$ is shown in Figure.2.

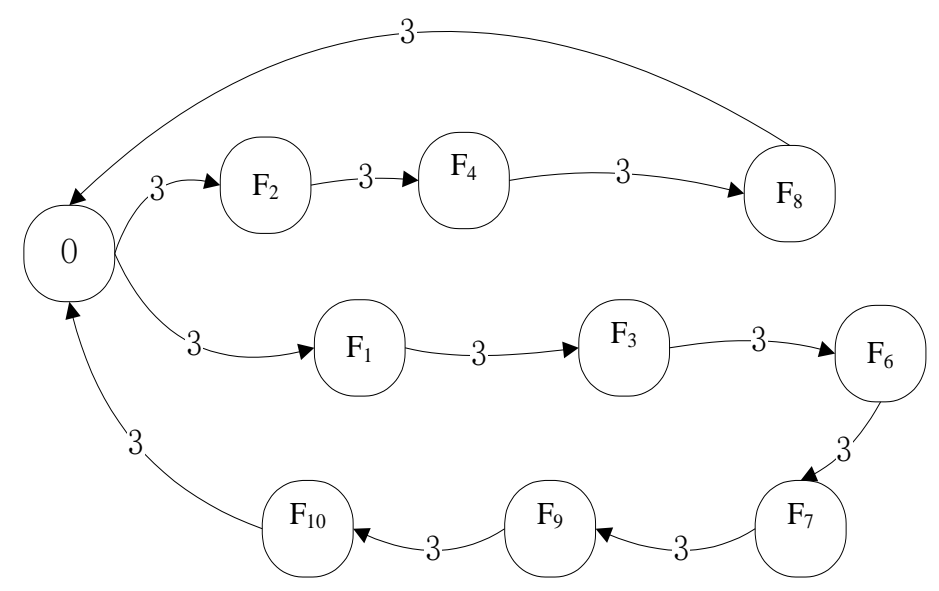

Figure 2. Flow Diagram of Scheduling and Allocating Scheme by ALG2

The scheduling result of $A L G_{3}$ is shown in Figure.3.1-Figure 3.4. 


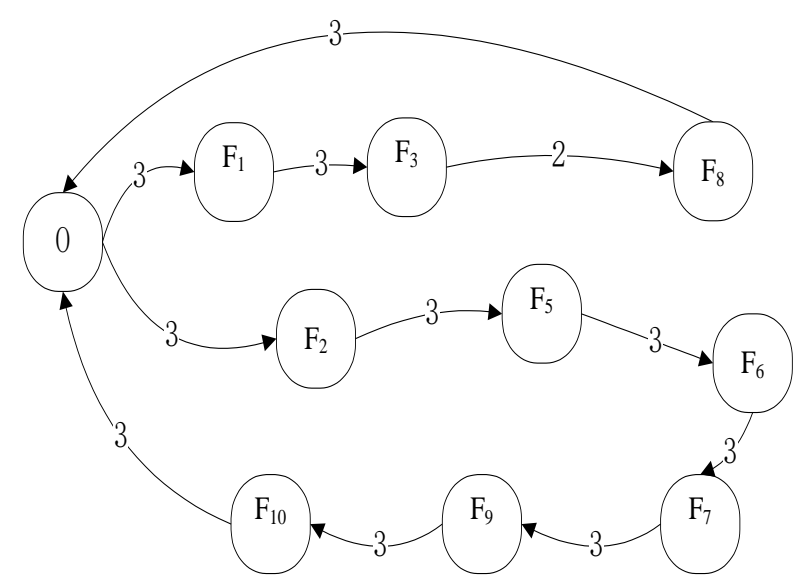

Figure 3.1. Flow Diagram of Scheduling and Allocating Scheme by AIG3.

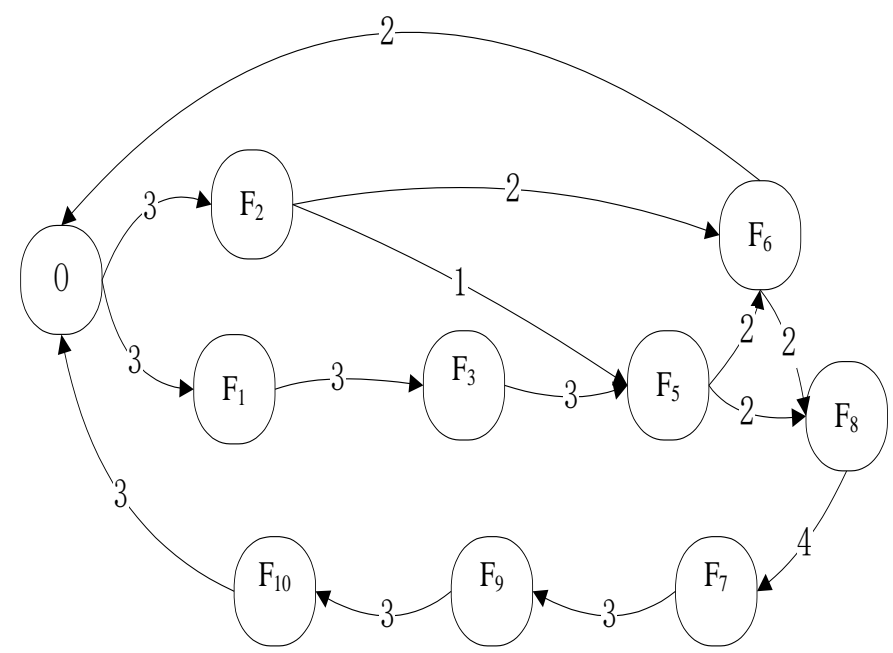

Figure 3.2. Flow Diagram of Scheduling and Allocating Scheme by AIG3.

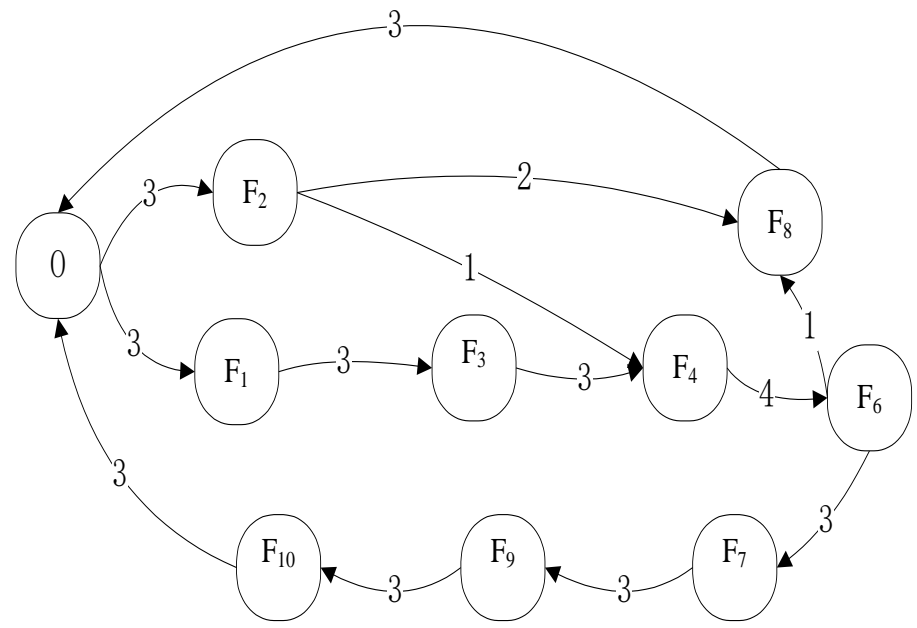

Figure 3.3. Flow Diagram of Scheduling and Allocating Scheme by AIG3 


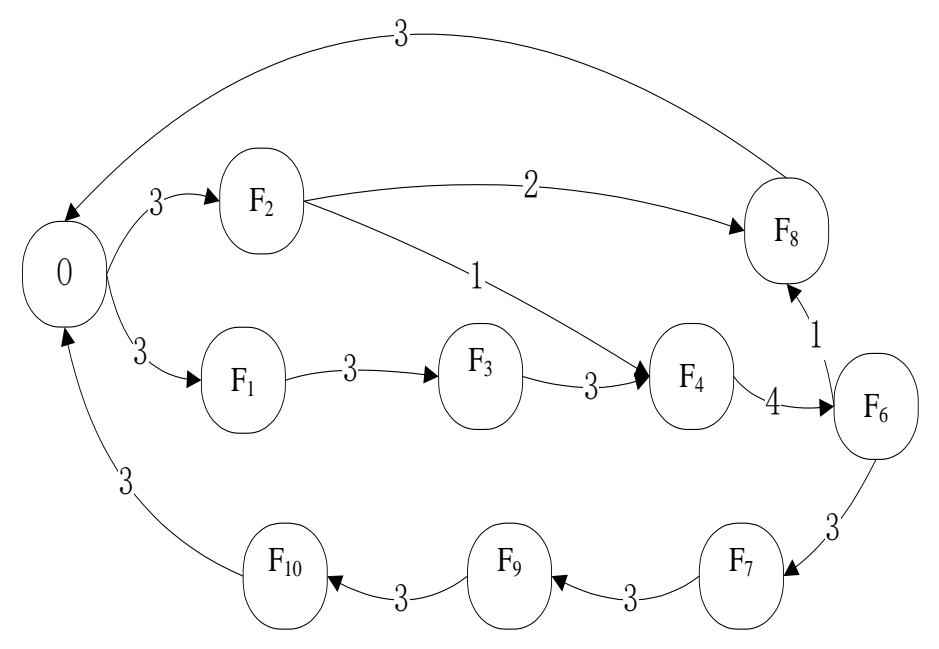

Figure 3.4. Flow Diagram of Scheduling and Allocating Scheme by AIG3.

Income, cost, profit, distance and input-output ratio of multiple scheduling and allocating schemes from three algorithms are calculated and the comparison results are listed in the table 3 .

Tab.3 Comparison between Multiple Scheduling and Allocating Schemes with Different Targets

\begin{tabular}{ccccccc}
\hline $\begin{array}{c}\text { algorit } \\
h m\end{array}$ & scheme & income/yuan & $\begin{array}{c}\text { cost } \\
\text { yuan }\end{array}$ & $\begin{array}{c}\text { Scheduling } \\
\text { distance/km }\end{array}$ & Profit/yuan & $\begin{array}{c}\text { input-output } \\
\text { ratio }\end{array}$ \\
\hline$A L G_{1}$ & 1 & $3.395 \times 10^{5}$ & $7.59 \times 10^{4}$ & $3.22 \times 10^{3}$ & $2.636 \times 10^{5}$ & $1: 3.47$ \\
$A L G_{2}$ & 2 & $3.321 \times 10^{5}$ & $4.25 \times 10^{4}$ & $1.94 \times 10^{3}$ & $2.896 \times 10^{5}$ & $1: 6.81$ \\
$A L G_{3}$ & $3-a$ & $3.321 \times 10^{5}$ & $4.25 \times 10^{4}$ & $1.94 \times 10^{3}$ & $2.896 \times 10^{5}$ & $1: 6.81$ \\
& $3-b$ & $3.279 \times 10^{5}$ & $3.89 \times 10^{4}$ & $1.80 \times 10^{3}$ & $2.89 \times 10^{5}$ & $1: 7.42$ \\
& $3-c$ & $3.279 \times 10^{5}$ & $3.90 \times 10^{4}$ & $2.21 \times 10^{3}$ & $2.889 \times 10^{5}$ & $1: 7.40$ \\
& $3-d$ & $3.321 \times 10^{5}$ & $4.28 \times 10^{4}$ & $2.19 \times 10^{3}$ & $2.893 \times 10^{5}$ & $1: 6.76$ \\
\hline
\end{tabular}

The scheduling and allocating schemes are obtained by three algorithms and evaluated by fuzzy analytic hierarchy process according to different scheduling and allocating targets $^{[13]}$. The comparison results are listed in the Table 4.

Table 4. Information of Comprehensive Evaluation and Ranking of Scheduling and Allocating Scheme

\begin{tabular}{c|ccccccccc}
\hline & \multicolumn{2}{c}{$\begin{array}{c}\text { High Profit and } \\
\text { Short distance }\end{array}$} & \multicolumn{2}{c}{$\begin{array}{c}\text { High Profit and } \\
\text { Short waiting time }\end{array}$} & \multicolumn{2}{c}{$\begin{array}{c}\text { High Profit and } \\
\text { High input-output ratio }\end{array}$} \\
\hline \multirow{3}{*}{$\begin{array}{c}\text { Comprehensive } \\
\text { evaluation }\end{array}$} & Rank & scheme & $\begin{array}{c}\text { Evaluation } \\
\text { Value }\end{array}$ & Rank & scheme & $\begin{array}{c}\text { Evaluation } \\
\text { Value }\end{array}$ & Rank & scheme & \begin{tabular}{c} 
Evaluation \\
and \\
\cline { 2 - 9 } rank
\end{tabular} \\
\cline { 2 - 9 } & 2 & $(3-b)$ & 0.986 & 1 & $(3-b)$ & 0.986 & 1 & $(3-b)$ & 0.986 \\
& 2 & $(3-a)$ & 0.964 & 2 & $(3-c)$ & 0.909 & 2 & $(3-c)$ & 0.981 \\
& 4 & $(3-d)$ & 0.964 & 3 & $(3-a)$ & 0.876 & 3 & $(3-a)$ & 0.942 \\
\hline
\end{tabular}




\begin{tabular}{c|ccccccccc}
\hline & 5 & $(3-c)$ & 0.874 & 5 & $(3-d)$ & 0.618 & 5 & $(3-d)$ & 0.930 \\
& 6 & $(1)$ & 0 & 6 & $(1)$ & 0.229 & 6 & $(1)$ & 0 \\
\hline
\end{tabular}

From the above analysis, only one feasible scheme can be obtained by $A L G_{1}$ and $A L G_{2}$. More than one feasible scheme can be obtained by $A L G_{3}$. When the target is High Profit and Short distance, the best scheme is (3-b) .when the target is High Profit and Short waiting time, the best scheme is (3-b). When the target is High Profit and High input-output ratio, the best scheme is $(3-b)$. So with the above comparison, all the best schemes are from the result of $A L G_{3}$.

\subsection{Analysis and Verification}

In order to verify the effectiveness of $A L G_{3}$, the further analysis and comparison are made at the following aspects. The average revenue per machinery calculated through $A L G_{1}, A L G_{2}$ and $A L G_{3}$, are compared when the parallel amount is 2, 3 and 4 . Five groups of farmland are generated randomly in the situation of different parallel amount. The amount of agricultural machinery is 6 and the amount of farmland is 10 .

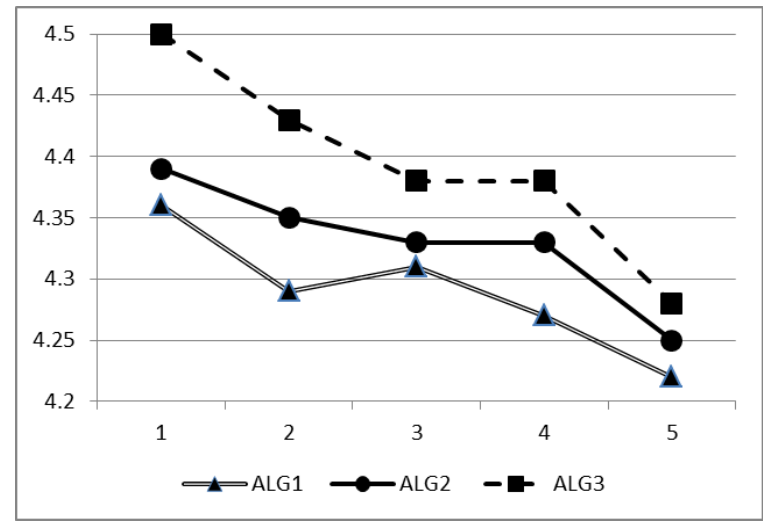

Figure 4.1 Comparison of Average Revenue of Single Machinery Among Three Algorithms when Parallel Amount is 2

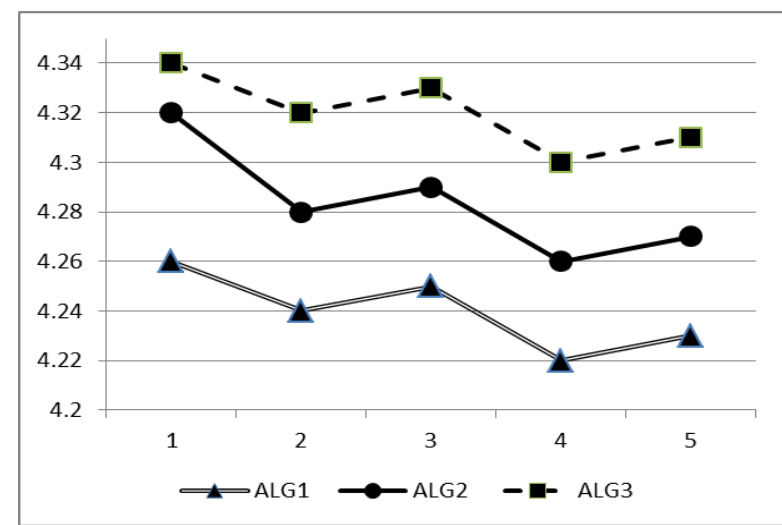

Figure 4.2 Comparison of Average Revenue of Single Machinery Among Three Algorithms when Parallel Farmland amount is 3 


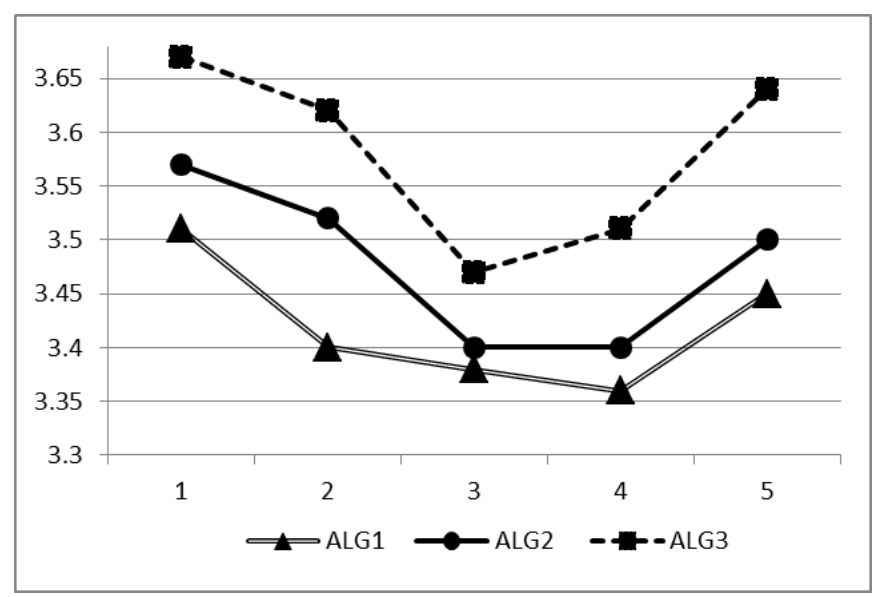

Figure 4.3 Comparison of average revenue of single machinery among three algorithms when parallel amount is 4

The results from fig4.1, 4.2, and 4.3 are shown that the average revenue per machinery from $A L G_{3}$ is higher than that of $A L G_{1}$ and $A L G_{2}$ when the parallel amount is 2, 3 and 4.

\section{Conclusions and Discussion.}

Agricultural machinery scheduling and allocating is a complex and huge problem, with many influential factors and complex relationship. The issues will be discussed here. Firstly, it is the quantity of machinery held by machinery owners. China is a huge agricultural country with low agricultural economy level and weak financial resources. The management of land is decentralized. It cannot be achieved that every household has a variety of agricultural machinery. So several machinery owners schedule and allocate agricultural machinery as a team together. Secondly, it is the problem of machinery fault. In order to ensure zero failures, the machinery owner will check agricultural machinery and troubleshoot risks and other issues before service. If the agricultural machinery failure still appeared and delay the scheduling time, machinery owners can consult with farmland owners. The allocating schemes are also obtained by Search-based Scheduling and Allocating Algorithm proposed in this paper after updating machinery and farmland information.

\section{Acknowledgements.}

This work was supported by the Major Program for science and technology Research of Hebei Higher Education Institutions (Grant No. Z2014168). The authors also gratefully acknowledge the helpful comments and suggestions of the reviewers, which have improved the presentation.

\section{References.}

[1] P. Bo, "Design and implementation of farm SMS center farms based on GPS and GSM", Journal of China Agricultural University, vol 2, (2005), pp. 70-73.

[2] C. Quanquan, "Applied research on farm machinery service information system", Science and Technology Information, vol 13, (2009), pp.14-15.

[3] G. Congjiang, "Application of digital command and control system in agricultural management", Agricultural Technology and Equipment, vol. 3, (2009), pp. 162-163.

[4] G. Hongpeng, L. Chen and Y. Yang, "Study on the decision support system of contract hire system of agricultural machines in China", Journal of Agricultural Mechanization Research, vol. 2, (2006), pp. 39-42.

[5] F. Zhang, G. Teng, "Research on Influenced Factors about Routing Selection Scheme in Agricultural Machinery Allocation", $4^{\text {th }}$ IFIP TC 12 Conference, CCTA2010, vol. 2, pp. 365-369. 
[6] F. Zhang, G. Teng, "Research on Multitask Collaborative Scheduling Problem with Heuristic Strategies", Applied Mechanics and Materials, vol. 66-68, (2011), pp758-763.

[7] F. Zhang, G. Teng, "Study on Farm Machinery Scheduling and Allocation Problem with Heuristic Priority Rules", ICIC Express Lettersvol. 6, (2012).

[8] Y. Lifeng and X. Xinmian, Current situation and development trend of agricultural mechanization on domestic and overseas. Journal of Hubei Agricultural Mechanization Research, (2007), vol. 6, pp. 36-37.

[9] Z. Xiuhua, "Study on the Service System in Trans-regional Harvesting Wheat Using Combine Harvester", Agricultural university of China, (2006).

[10] Y. Yingchun, L. Xiaoping, W. Qian, "Grid Workflows Schedule Based on Priority Rules”, Acta Electronica Sinica, vol. 37, (2009), pp. 1457-1464.

[11] J. Buddhakulsomsiri, D.S. Kim, "Priority rule-based Heuristic for multi-mode resource-constrained project scheduling problems with resource vacations and activity splitting", European Journal of Operational Research, (2007), vol. 178, pp. 374-390.

[12] L. Ming, W. Cheng, Y. Yingjie, "Genetic Algorithm Method Based on Combinatorial Rules in Identical Parallel Machine Scheduling Problem", Acta Electronica Sinica, vol. 28, (2000), pp. 52-54.

[13] F. Zhang, "Study on Farm Machinery Scheduling and Allocating Strategies", Agricultural University of Hebei, (2012).

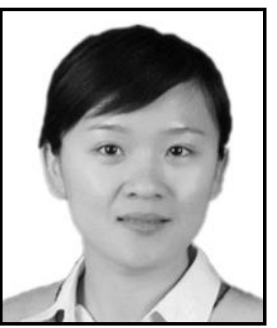

\section{Authors}

Fan Zhang, She is working as a lecturer at School of Information Science and Technology, Agricultural University of Hebei. I received Ph.D. degree in 2012 and the field of research is artificial intelligence applied technology.

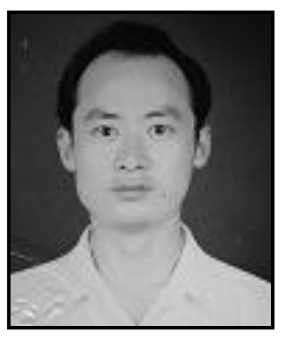

Yueli $\mathbf{L i}, \mathrm{He}$ is working as a lecturer at School of Information Science and Technology, Agricultural University of Hebei. His field of research is computer network and database technology, artificial intelligence applied technology.

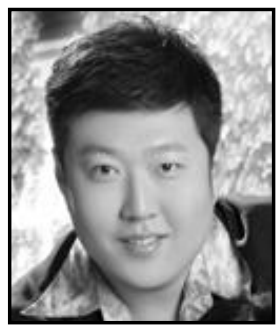

Chen Chen, He is working as a lecturer at School of Information Science and Technology, Agricultural University of Hebei. His field of research is artificial intelligence applied technology. 
International Journal of Grid and Distributed Computing

Vol. 9, No. 1 (2016) 